\title{
Improving Performance of Free Space Optics Link Using Array of Receivers in Terrible Weather Conditions of Plain and Hilly Areas
}

\author{
Amit Gupta \\ Professor, Department of ECE \\ Chandigarh University, \\ Gharuan, India \\ Surbhi Bakshi \\ Associate Professor, Department of ECE \\ Chandigarh University, \\ Gharuan, India
}

\author{
Shaina \\ Research Scholar, Department of ECE \\ Chandigarh University, \\ Gharuan, India \\ Mandeep Chaudhary \\ School of Engineering \& Digital arts \\ University of Kent \\ Canterbury,UK
}

\begin{abstract}
Free-space optical (FSO) communication is a cost effective and high data rate access technique, which has been proving itself a best alternative to radio frequency technology. FSO link provides high bandwidth solution to the last mile access bottleneck. However, for terrestrial communication systems, the performance of these links is severely degraded from atmospheric loss mainly due to fog, rain and snow. So, a continuous availability of the link is always a concern. This paper investigates the dreadful weather effects such as rain, fog, snow, and other losses on the transmission performance of FSO systems. The technique of using an array of receivers for improving the performance of FSO links is explored in this paper. It involves the deployment of multiple photo detectors at the receiver end to mitigate effects of various weather conditions. The performance of the proposed system is evaluated in terms of bit error rate, received signal power, $Q$ - factor and height of eye diagram. The influence of various weather conditions of plain and hilly areas are taken into consideration and results are compared with conventional FSO links.
\end{abstract}

Keywords-Free space optics (FSO) communication; Array of photo detectors; Bit Error Rate (BER); Eye diagram; Quality factor ( $Q$ factor); Bad weather effects

\section{INTRODUCTION}

The optical wireless communication (OWC) systems have attracted a lot of interest of the users because they can solve the last mile problem in urban environments. OWC, also recognized as free space optical (FSO) communication, has emerged as a commercially feasible alternative to radio frequency (RF) and millimetre waves wireless communication for reliable and rapid deployment of data and voice networks. FSO communication using high bandwidth transmission links has enormous potential to serve for requirements of high data rate transmissions. License free bandwidth, high carrier frequency (range $20 \mathrm{THz}-375 \mathrm{Thz}$ ), easy deployment, appreciable security of data, avoiding electromagnetic pollution, low power consumption enables FSO links to provide high data rates communications[1]. Its various advantages over existing Radio Frequency (RF) technologies like wider bandwidth that can support a large number of users without any delay or interference in communication, have increased its demand in the market.

Despite of being on the list of most desirable technologies of the next generation, its deployment is highly dependent on atmospheric variations thus related to its reliability and availability issues. Fog, snow and clouds scatter or absorb the optical signal, which causes transmission errors. Maintaining a clear line of sight (LOS) between transmitter and receiver is also one of the major challenges in establishing optical wireless links in the free space [6]. The LOS is disturbed due to atmospheric influences like fog, rain, snow, dust, sleet, clouds or temporary physical obstructions like birds and airplanes. Various researchers have come up with the results that optical attenuation can reach up to $128 \mathrm{~dB} / \mathrm{km}$ in heavy fog and snow conditions in different areas [7]. The scattering, absorption and refraction of light signals reduce the link capacity and availability in different weather conditions.

To lessen these effects, techniques like using multiple transmit lasers and multiple receive apertures can be applied [8-9]. The performance of FSO links in the presence of atmospheric turbulence had been analyzed using spatial diversity [10-11]. To calculate the error rate performance, outage probability and diversity gain for multi-input multioutput FSO links, the combined effect of atmospheric turbulence and misalignment was also considered [12-13]. Then the effect of weather conditions was taken into account using array of receivers [14-16].

But the effect of weather conditions of hilly areas like heavy fog, wet snow, dry snow etc was not discussed by researchers in previous literature. The consideration of these parameters cannot be ignored while installation of FSO link especially in hilly areas. In this paper a comprehensive analysis of FSO link in all weather conditions has been performed using one of the most important approaches of array of photo detectors to reduce the effects of attenuation on received signal. At an ideal case, the only cause of signal attenuation is distance 
of transmission. So, the additional losses we have taken into account are due to weather conditions only and other losses are considered to be $0 \mathrm{~dB} / \mathrm{km}$. The study of bit error rate, height of eye diagram, $\mathrm{Q}$ factor and maximum received power is taken into account for studying the performance of FSO link.

The paper is organized as: After the introduction of FSO systems, system analysis of proposed FSO model is provided and various parameters that affect the quality of the signal in the link are discussed in section II. In Section III, the results obtained after simulations are evaluated for both hilly and plain areas using array of receivers. Finally, conclusions are drawn in Section IV.

\section{SYSTEM ANALYSIS}

A synoptic diagram of the considered system model is depicted in Figure 1 below. The block diagram shows the three key function elements of FSO system that are the transmitter, the atmospheric channel and the receiver. The transmitter which is used for converting electrical signal into optical signal consists of a modulator, a laser driver, a laser and a power meter.

The modulator used in the link converts the information into the desired signal and controls the amplitude of an optical signal. Laser driver provides the power to the laser for its proper functioning and helps to prevent aging and other environmental effects of laser. The range of the link for evaluating the performance is chosen as $500 \mathrm{~m}$ and the transmission wavelength chosen for the working of laser is $1550 \mathrm{~nm}$ which is the 3rd optical window of wireless transmission. It is chosen to work on this wavelength as the functioning of FSO link is more robust and safe for human eye at this value [2-3].
The information signal is transmitted over FSO channel where it undergoes attenuation and power loss as a result of absorption, scattering and turbulence. At the receiver end, the signal is amplified and detected by an array of receivers which improve the overall efficiency and accuracy of the system. The filter and regenerator are used to preserve the wave shape of the signal. Power meter and BER analyser are used to measure the parameters of received signal. The data rates up to 100 Gb/s can be achieved using FSO technology [4-5].

Attenuation present in the atmosphere of the system can affect its performance. Atmospheric attenuation and geometric losses constitute all attenuation. It is the effect of particles present in the air for e.g. haze, rain, fog, snow etc. These particles can stay a longer time in the atmosphere. So, attenuation values depend upon the visibility level at that time. To reduce these effects, a system is proposed that can work properly under these conditions. The value of parameters on which the system is operating is mentioned in table 1.

The total attenuation of wireless medium communication system can be estimated [17] as:

$$
\alpha=\alpha \mathrm{fog}_{\gamma}+\alpha \operatorname{snow}_{\gamma}+\alpha \operatorname{rain}_{\gamma}+\alpha \text { scattering }_{\gamma}, \mathrm{dB} / \mathrm{km}
$$

where, $\alpha=$ attenuation and

\section{$\gamma=$ is transmission wavelength in $\mu \mathrm{m}$}

The main attenuation factor for optical wireless links is fog, but the attenuation caused by an effect of rain cannot be ignored, especially in environments where rain is more frequent than fog.
Transmitter

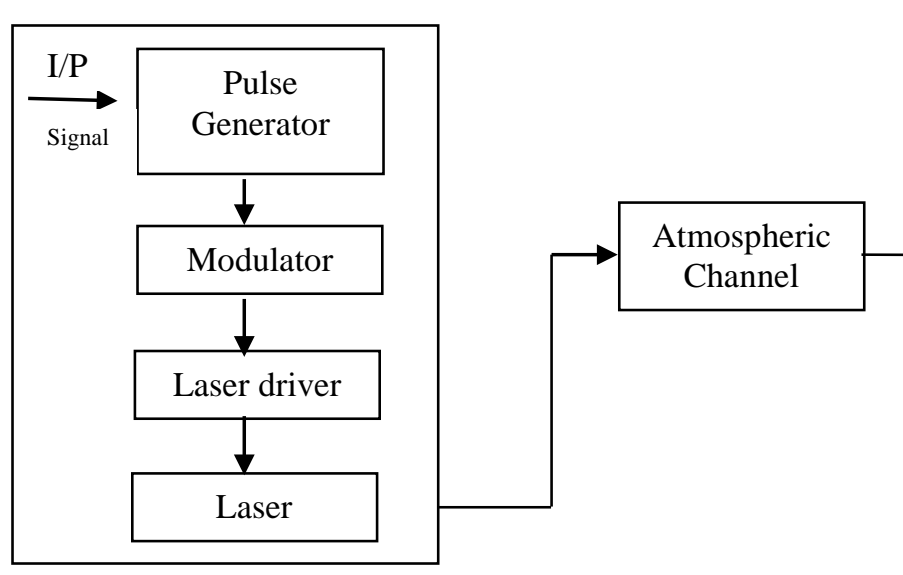

Receiver

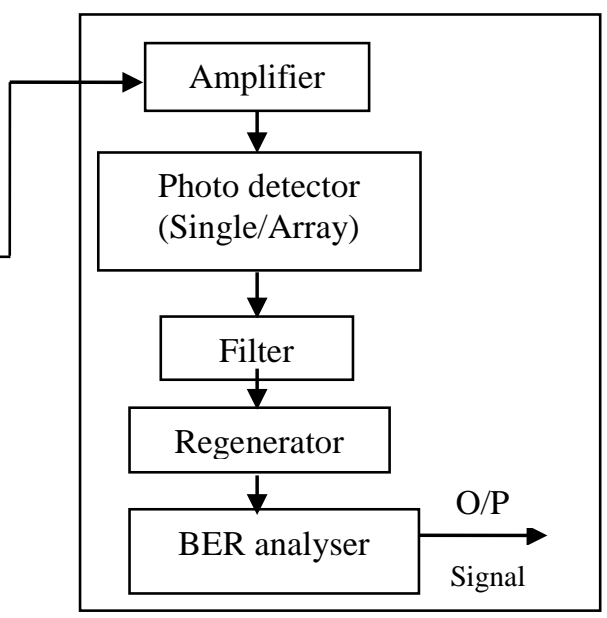

Fig. 1. Block diagram of FSO link 
TABle I. Proposed Operating Parameters For Free Space OPTICAL COMMUNICATION SYSTEMS

\begin{tabular}{cc}
\hline Operating parameters & Value \\
\hline Signal transmitted power (plain areas) & $1 \mathrm{~mW}$ \\
Signal transmitted power (hilly areas) & $20 \mathrm{~W}$ \\
Attenuation (plain areas) & $0-43 \mathrm{~dB}$ \\
Attenuation (hilly areas) & $110-128 \mathrm{~dB}$ \\
No. of photo detectors used & 8 \\
Range of Link & $500 \mathrm{~m}$ \\
Operating signal wavelength, & $1550 \mathrm{~nm}$ \\
Transmitter lens diameter & $100 \mathrm{~cm}$ \\
Receiver aperture diameter & $50 \mathrm{~cm}$
\end{tabular}

Let $\mathrm{R}$ be the rain rate in $\mathrm{mm} / \mathrm{h}$, the specific attenuation of optical wireless link is given by [18]:

$\alpha_{\text {rain }}=1.076 \mathrm{R}^{0.67} \mathrm{~dB} / \mathrm{km}$

If $\mathrm{S}$ is the snow rate in $\mathrm{mm} / \mathrm{h}$ then specific attenuation in $\mathrm{dB} / \mathrm{km}$ is given by [19] as:

$$
\alpha_{\text {dry snow }}=\mathrm{aS}^{\mathrm{b}} \mathrm{dB} / \mathrm{km}
$$

If $\lambda$ is the wavelength, the parameters $a$ and $b$ for dry snow is given as the following:

$\mathrm{a}=5.42 \times 10-4 \lambda+5.495876, \mathrm{~b}=1.38$

The specific attenuation in the case of wet snow can be expressed as the following formula [20]:

$$
\alpha_{\text {wet snow }}=\mathrm{h} \mathrm{S}^{\mathrm{g}} \mathrm{dB} / \mathrm{km}
$$

The parameters $\mathrm{h}$ and $\mathrm{g}$ for wet snow are as, $\mathrm{h}$ $=1.023 \times 10-4 \lambda+3.7855466, \mathrm{~g}=0.72$

The amount of received power is proportional to the amount of power transmitted and the area of the collection aperture but inversely proportional to the square of the beam divergence and the square of the link range. It is also inversely proportional to the exponential of the product of atmospheric attenuation coefficient times the link range [21-22].

$$
\mathrm{P}_{\text {received }}=\mathrm{P}_{\text {received }} * \frac{\mathrm{d}_{2}^{2}}{[\mathrm{~d} 1+(\mathrm{D} * \mathrm{R})]^{2}} * 10^{(-\mathrm{a} * \mathrm{r} / 10)}
$$

Where, $\mathrm{P}=$ power,

$\mathrm{d} 1$ = transmit aperture diameter $(\mathrm{m})$,

$\mathrm{d} 2$ = receive aperture diameter $(\mathrm{m})$,

$\mathrm{D}=$ beam divergence $(\mathrm{mrad}), \mathrm{R}=$ range $(\mathrm{km})$,

$\mathrm{a}=$ atmospheric attenuation factor $(\mathrm{dB} / \mathrm{km})$.

Also, the bit error rate can also be expressed in terms of signal to noise ratio (SNR) as:

$$
\mathrm{BER}=\frac{2}{\pi \cdot \mathrm{SNR}} \cdot \exp \left(-\frac{\mathrm{SNR}}{8}\right)
$$

\section{RESUlts AND PERFORMANCE EVALUATION}

The model has been investigated to show the weather effects on the transmission and overall performance on free space communication in hilly and plain areas by using single photo detector and an array of photodetectors. FSO system with link range $500 \mathrm{~m}$ operating at a wavelength of $1550 \mathrm{~nm}$ is considered such that it can show useful results over a wide range of weather conditions. The values of attenuation effecting information signal considered in table 2 are taken from [6].

TABLE II. COMPARISON OF OUTPUTS OF BER ANALYSER IN PLAIN AREAS

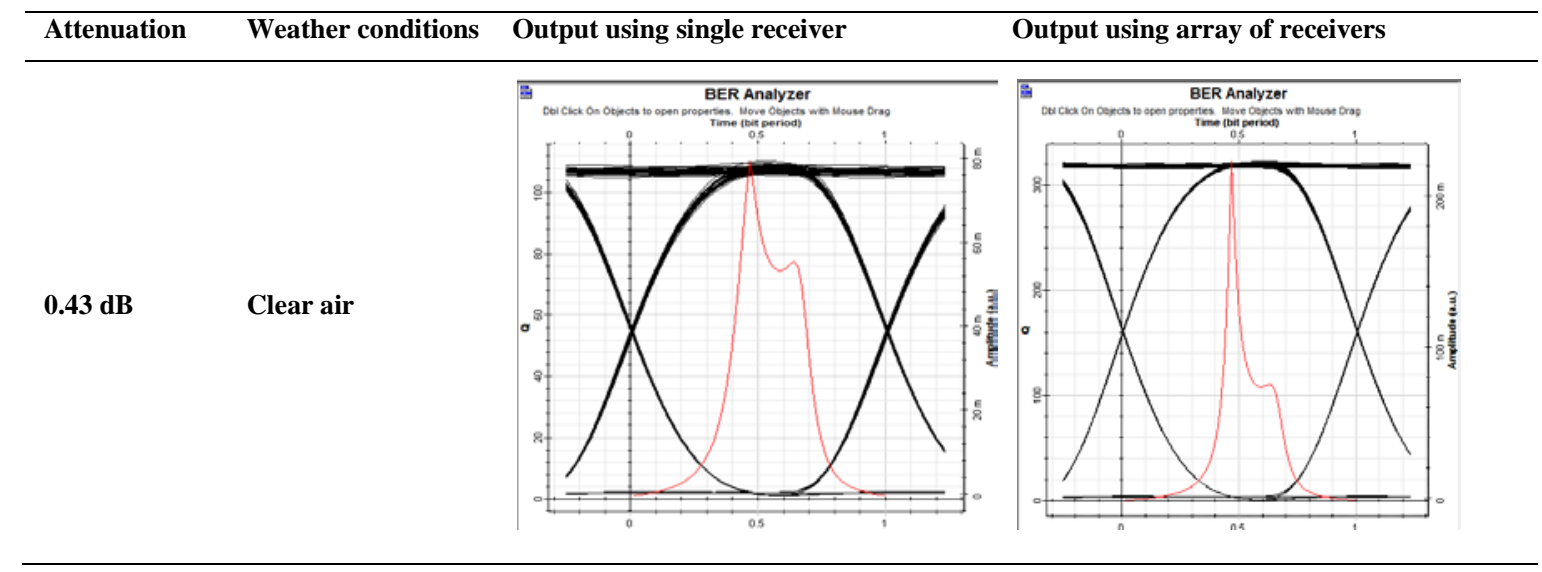


$4.2 \mathrm{~dB}$

$5.8 \mathrm{~dB}$

$9.2 \mathrm{~dB}$

$20 \mathrm{~dB}$

Light fog

$42.2 \mathrm{~dB}$

Haze
Moderate rain

Heavy rain
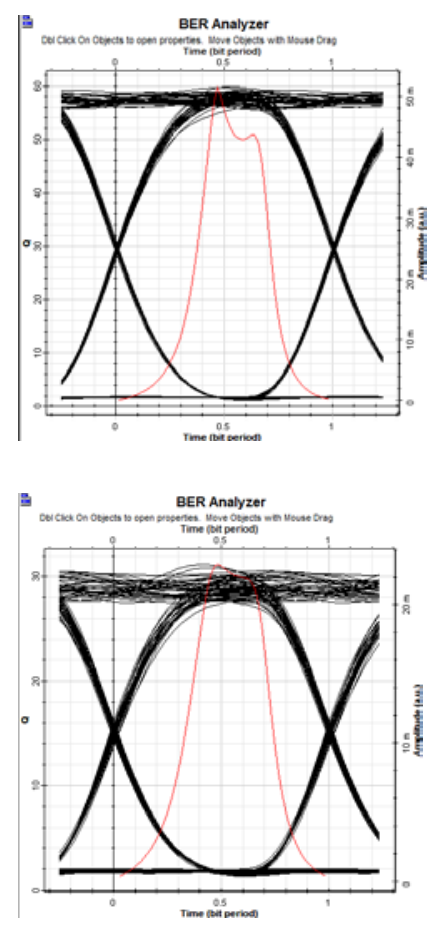

s
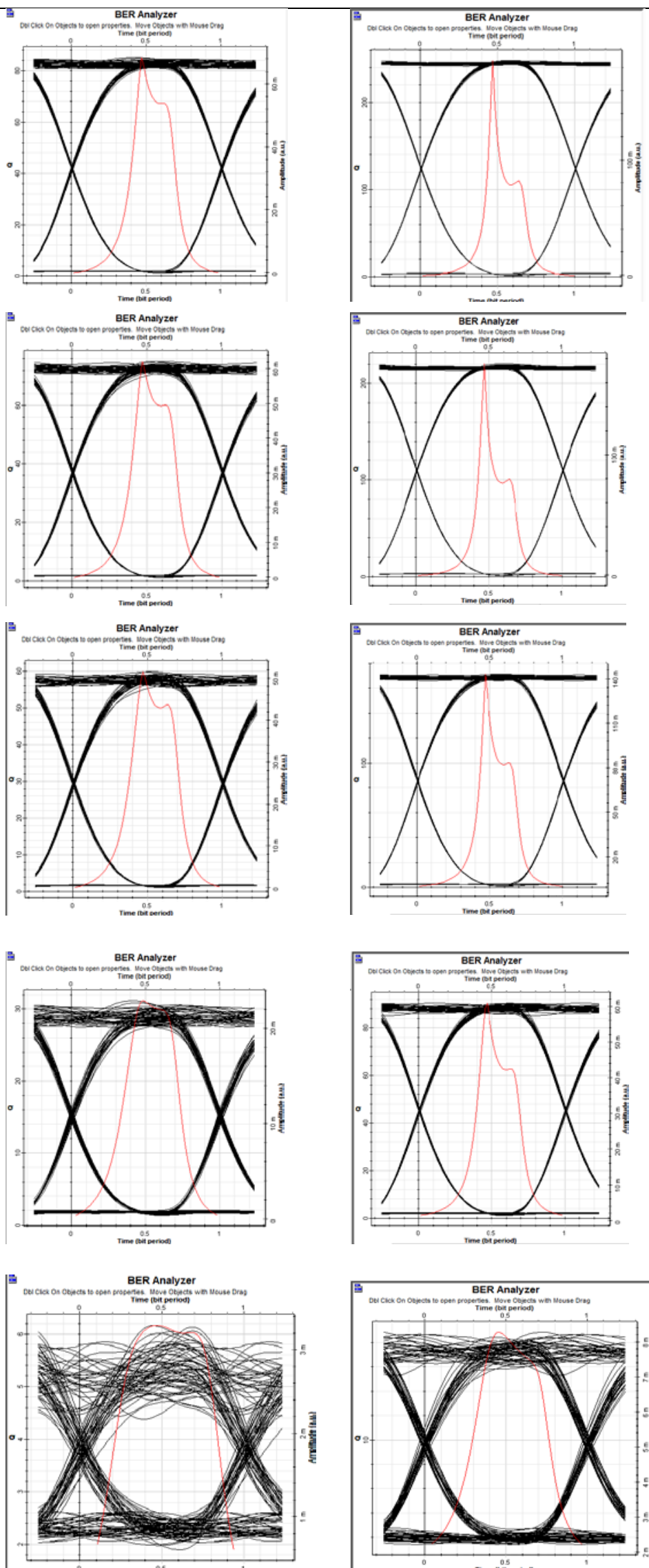

Timen ist teetiont

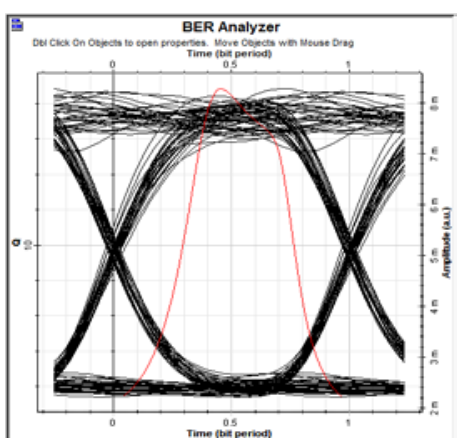


Table 2 shows the output of BER analyser for FSO link located in plain areas. The comparison is showing the improvement in the output when more than one receivers are inserted in the link. It can be seen than width and height of eye have increased and curve of $\mathrm{Q}$ factor has become sharp after using array of receivers at different values of attenuation. Figures in the table have proved that received signal power decreases with increasing atmospheric attenuation for in the presence of bad weather effects. But using an array of photo detectors has presented the highest received signal power compared to a single receiver. From the above discussion it is clear that array of receivers is giving better results in these weather conditions also. So, this technique can be further implied on the weather conditions of hilly areas too.

TABLE III. COMPARISON OF OUTPUTS OF BER ANALYSER IN HILLY AREAS

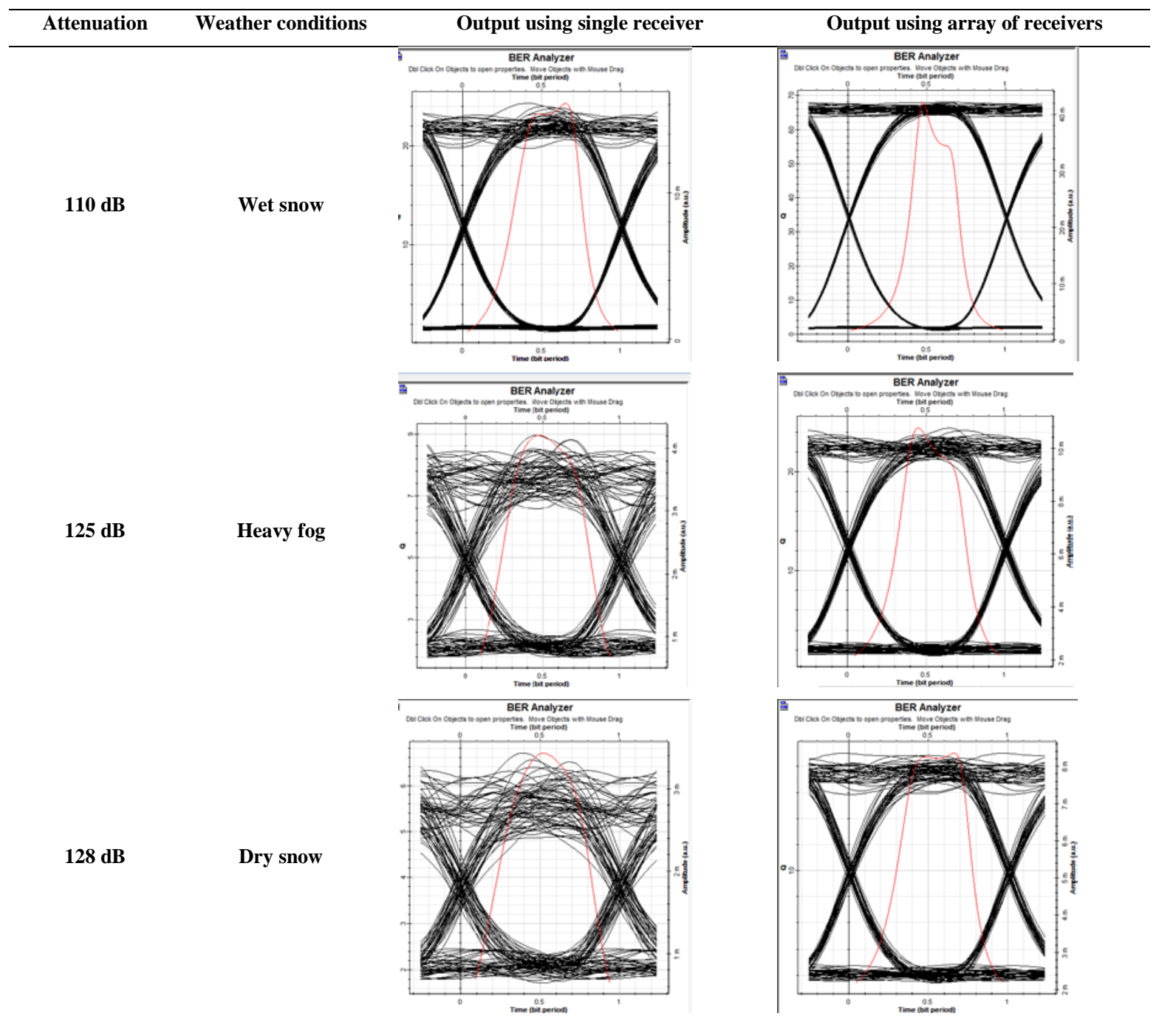

Similarly, Table 3 is the comparison of the output of BER analyzer in hilly areas. The values of attenuation of the signal effecting communication considered in table 3 in taken from [7]. The value of attenuation in hilly areas is very large as compared to plain areas.

So using an array of receivers in hilly areas gives very effective results by improving values of simulation parameters far better than optimum values.
The figures show that even in high attenuation conditions FSO systems can be deployed reliably by slightly modifying the conventional FSO systems.

The system operation characteristics have been plotted under varying weather conditions using different simulation parameters. A brief comparison is made to show the improvement in all simulation parameters using more than one receiver for receiving the information signal. 


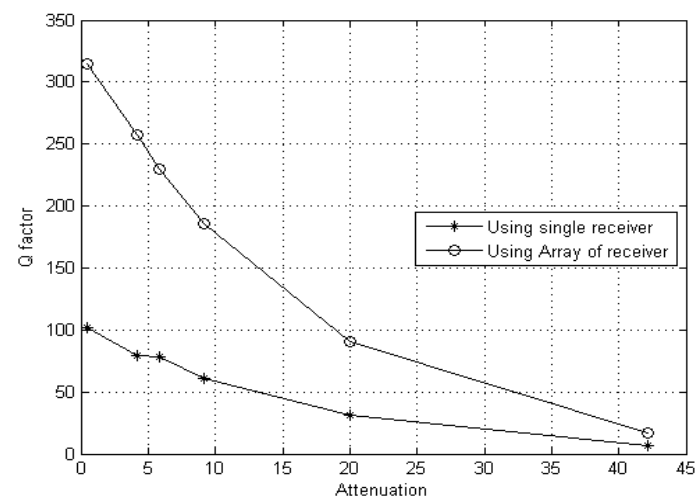

Fig. 2. Comparison of $\mathrm{Q}$ factor in weather conditions of plain areas using single and array of Photo detectors

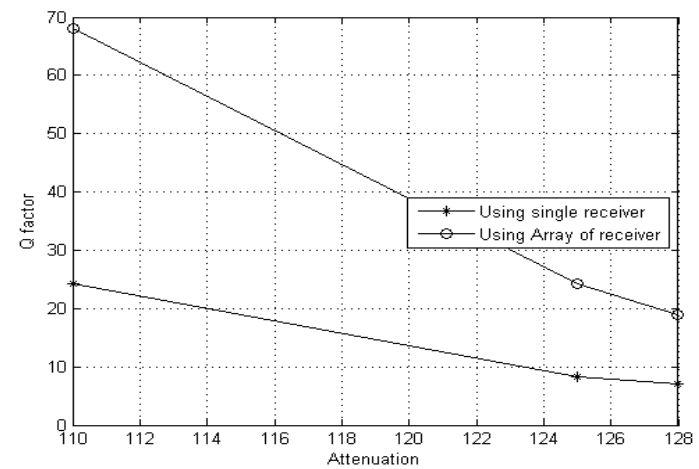

Fig. 3. Comparison of $\mathrm{Q}$ factor in weather conditions of hilly areas using single and array of Photo detectors

The graphs in figure 2 and 3 show the comparison of various values of $\mathrm{Q}$ factor of system model, as a result of using single receiver and array of receivers at different weather conditions of plain areas and hilly areas. The curve in figure 2 shows that, at transmitter power of $1 \mathrm{~mW}$ there is a large difference in output signals of both the cases. Below $20 \mathrm{~dB}$ attenuation the technique employed is improving the quality of the received signal in huge ratio. After $20 \mathrm{~dB}$ the results start decreasing linearly with increasing attenuation and for the values above $40 \mathrm{~dB}$ there are not many variations in the results.

In figure 3 also, the results have assured that the $\mathrm{Q}$ factor of the system increases with increasing number of photo detectors in the link. It is observed that the quality of a signal received using an array of receivers is much better than the quality of the signal using single detector under different attenuation conditions. There is a significant difference in the value of $\mathrm{Q}$ factor at $128 \mathrm{~dB}$, thus improving the reliability of the communication in bad weather conditions.

Figures 4 and 5 have demonstrated that the width of eye increases after the use of array of receivers in the link in both plain as well as hilly areas because the resultant signal is chosen such that it have maximum signal to noise ratio thus the opening of eye is more as compared to signal detected with single photo detector.

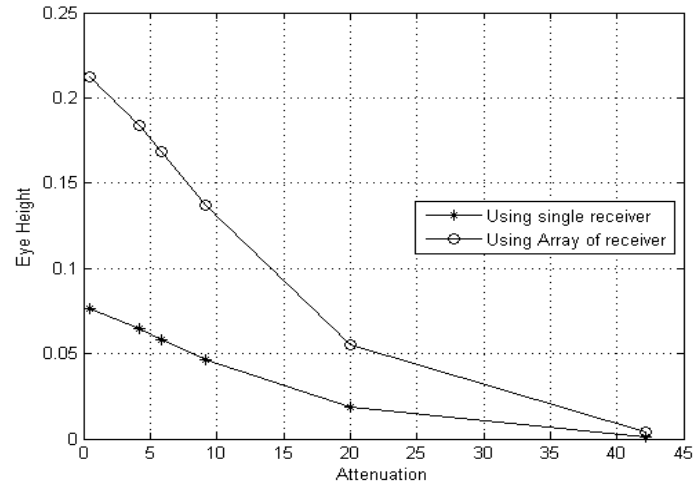

Fig. 4. Comparison of Eye height in weather conditions of plain areas using single and array of Photo detectors

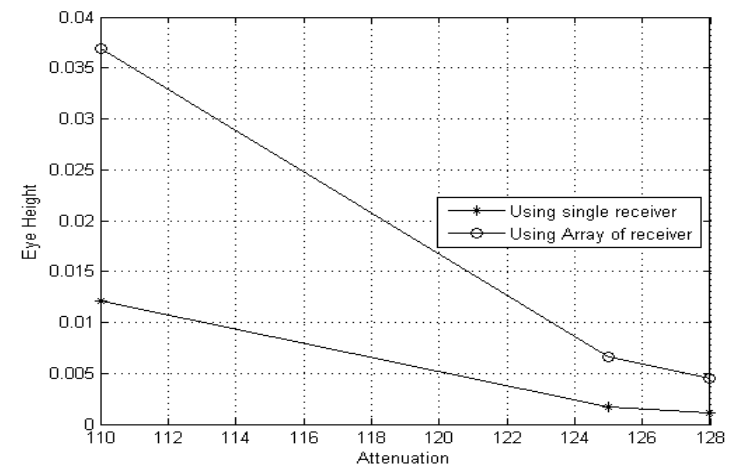

Fig. 5. Comparison of eye height in weather conditions of hilly areas using single and array of Photo detectors

In figure 4 , there is a significant difference in the values before $20 \mathrm{~dB}$ attenuation but after $20 \mathrm{~dB}$ it is almost same. But figure 5 illustrates that in hilly areas using this technique is quite helpful in removing the noise and jitter from the signal.

At $128 \mathrm{~dB}$, the value of eye height in the conventional system is 0.0012 which is improved to 0.0036 using array of receivers.

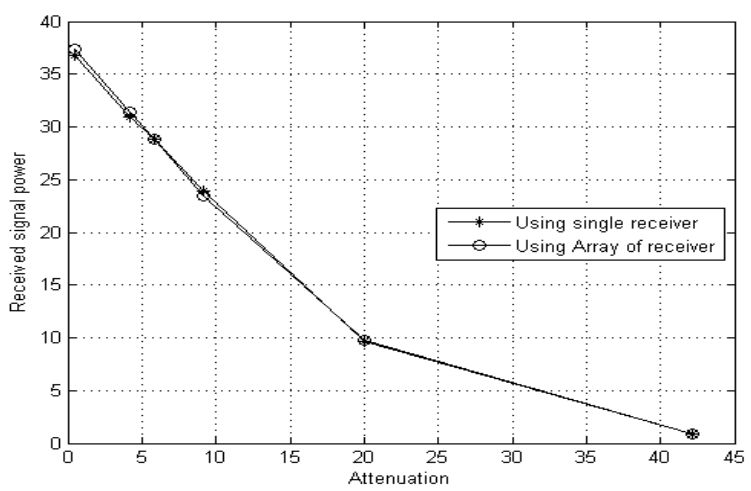

Fig. 6. Comparison of received signal power in weather conditions of plain areas using single and array of Photo detectors 


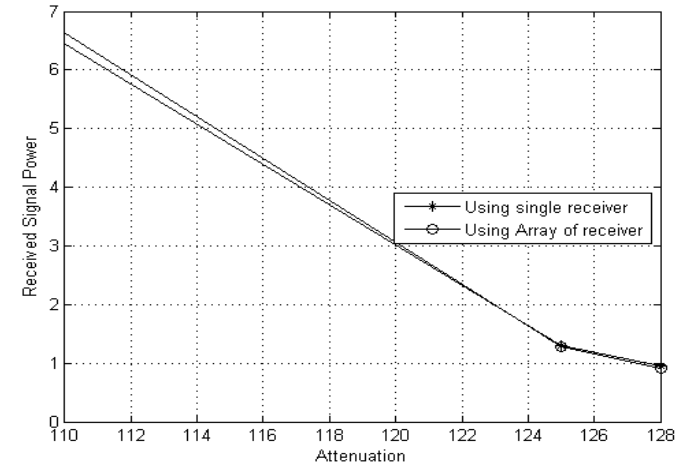

Fig. 7. Comparison of received signal power in weather conditions of hilly areas using single and array of Photo detectors
Figures 6 and 7 are indicating that with an increase in a number of photo detectors at the receiver end, there is a slight increase in received signal power because the multiple numbers of detectors are detecting the same signal independently. The final signal obtained is the maximum value of all detected signals.

Finally, a comprehensive comparison has been presented in an organized manner among the performances of links having single photo detector and multiple photo detectors in tabular form. Table 4 is illustrating the values of simulation parameters analyzed in plain areas with transmission power one $\mathrm{mW}$. It can be clearly visualized that in the case of an array of photo detectors, there is a significance decrease in bit error rate. Also the values of $\mathrm{Q}$ factor, the height of eye and received signal power increases with the introduction of more than one photo detectors in the link.

TABLE IV. EVAluation of FSO LinK In Plain AREAS With POWER $1 \mathrm{MW}$

\begin{tabular}{|c|c|c|c|c|c|}
\hline & & Max. Q factor & Min. BER & Eye height & $\begin{array}{l}\text { Received signal } \\
\text { power(mW) }\end{array}$ \\
\hline \multirow{6}{*}{$\begin{array}{l}\text { Single } \\
\text { photo } \\
\text { detector }\end{array}$} & Clear air (0.43 & 102.192 & 0 & 0.076034 & 36.7936 \\
\hline & Haze (4.2dB) & 79.0142 & 0 & 0.0647861 & 30.911234 \\
\hline & Moderate rain (5.8dB) & 78.2872 & 0 & 0.0583843 & 28.845105 \\
\hline & Heavy rain $(9.2 \mathrm{~dB})$ & 60.5079 & 0 & 0.0461851 & 23.91591 \\
\hline & Light fog (20 dB) & 30.7312 & 7.34165e-208 & 0.0184382 & 9.69035 \\
\hline & Moderate fog (42.2 dB) & 6.93705 & $1.83037 \mathrm{e}-12$ & 0.00107621 & 0.90622 \\
\hline \multirow{6}{*}{$\begin{array}{l}\text { Array of } \\
\text { photo } \\
\text { detectors }\end{array}$} & Clear air (0.43 & 314.806 & 0 & 0.21236 & 37.388885 \\
\hline & Haze (4.2dB) & 257.198 & 0 & 0.183567 & 31.362605 \\
\hline & Moderate rain (5.8dB) & 229.584 & 0 & 0.168624 & 28.845105 \\
\hline & Heavy rain (9.2dB) & 186.242 & 0 & 0.136811 & 23.480854 \\
\hline & Light fog (20 dB) & 90.6124 & 0 & 0.055339 & 9.8212256 \\
\hline & Moderate fog (42.2 dB) & 17.0842 & 8.87462e-66 & 0.00437094 & 0.920583 \\
\hline
\end{tabular}

TABLE V. EVALUATION OF FSO LiNK IN HILly AREAS WITH POWER 20W

\begin{tabular}{llllll}
\hline & & Max. Q factor & Min. BER & Eye height & $\begin{array}{l}\text { Received signal } \\
\text { power(mW) }\end{array}$ \\
\hline & Wet snow $(110 \mathrm{~dB})$ & 24.2834 & $1.12641 \mathrm{e}-130$ & 0.0121424 & 6.4458854 \\
$\begin{array}{l}\text { Single photo } \\
\text { detector }\end{array}$ & Heavy fog $(125 \mathrm{~dB})$ & 8.19081 & $1.13342 \mathrm{e}-16$ & 0.0017453 & 1.3038745 \\
& Dry snow $(128 \mathrm{~dB})$ & 7.04754 & $8.40774 \mathrm{e}-13$ & 0.0011057 & 0.9438791 \\
\hline & Wet snow $(110 \mathrm{~dB})$ & 68.0498 & 0 & 0.0369363 & 6.6352527 \\
$\begin{array}{l}\text { Array of photo } \\
\text { detectors }\end{array}$ & Heavy fog $(125 \mathrm{~dB})$ & 24.1941 & $2.00845 \mathrm{e}-104$ & 0.0065796 & 1.2833537 \\
& & & & & \\
& Dry snow $(128 \mathrm{~dB})$ & 19.0077 & $8.40774 \mathrm{e}-13$ & 0.0044685 & 0.9144441 \\
\hline
\end{tabular}


The performance of link in hilly areas for different cases is summarized in Table 5 . It shows the values of various parameters in hilly areas, where attenuation is very high as compared to plain areas. So, the power used for transmission of signal in hilly areas is $20 \mathrm{~W}$. The quality of received signal is improving as the values of simulation parameters are attaining optimum values.

It can be clearly visualized from the above results that as the number of photo detectors are increased at the receiver end; it is possible to obtain performance that may not be possible by using other techniques like increasing the transmitter power or aperture averaging.

\section{CONCLUSION}

In this paper, the performance of the free space optical communication systems under the effects of bad weather conditions especially for heavy rain, fog, dry and wet snow has been analyzed. The performance of link is investigated for these conditions and is further improved by the technique of using an array of receivers. The results reveal that use of array of receivers is advantageous over that of a single receiver in FSO link for detecting the signal more accurately as the quality factor of received signal is improved by approximately $28 \%$ in all the cases under consideration. With further research and development, communication in FSO system can also be enhanced at higher data rate over a longer link range under all weather conditions and atmospheric turbulences to enhance the usage of free space optics technology.

\section{REFERENCES}

[1] F. Nadeem, V. Kvicera, M. S. Awan, E. Leitgeb, S. S. Muhammad, G. Kandus, "Weather Effects on Hybrid FSO/RF Communication Link," IEEE J. On selected areas in Comm., Vol.27, No. 9, pp. 1687-1696, Dec. 2009

[2] H.H. Refai, J.J. Sluss Jr., H.H. Refai, "Comparitive study of performance of analog fiber optic links versus free- space optical links" J. of Optical Engineering, Vol. 45, No.2, Feb. 2006

[3] S. Saini, A. Gupta," Investigation to find optimal modulation format for low power inter-satellite optical wireless communication (LP-IsOWC)", Eleventh International conference on Wireless and Optical Communication Networks, pp. 1-4, 2014

[4] V. Sarup, A. Gupta” Performance analysis of an ultra high capacity 1 Tbps DWDM-RoF system for very narrow channel spacing”, Eleventh International conference on Wireless and Optical Communication Networks, pp. 1-5, 2014

[5] N. Cvijetic, Q. Dayou, Y. Jianjun, H. Yue-Kai, W. Ting, "100 Gb/s per channel free space optical transmission with coherent detection and MIMO processing,"in Proc. ECOC, pp.1-2, 2009

[6] B. He, R. Schober,” Bit-Interleaved Coded Modulation for Hybrid RF/FSO Systems", IEEE Trans. on Comm., Vol. 57, No. 12,pp. 37533763, Dec. 2009

[7] A.N.Z. Rashed, M.M.E. El-Halawany, ”Transmission characteristics evaluation under bad weather conditions in optical wireless links with different optical transmission windows", Wireless Personal Communications, Springer, Vol. 71, No. 2, pp. 1577-1595, July 2013

[8] A. K. Majumdar and J. C. Riclkin, "Free-space laser communications," in Principles and Advances. New York, NY, USA: Springer-Verlag, 2007.
[9] M. M. Ibrahim and A. M. Ibrahim, "Performance analysis of optical receivers with space diversity reception," IEE Proc. Commun., vol. 143, no. 6, pp. 369-372, Dec. 1996.

[10] S. Saini, A. Gupta," Modeling and Performance Analysis of DWDM Based 100 Gbps Low Power Inter-satellite Optical Wireless Communication (LP-IsOWC) System”, SOP transactions on signal processing, Vol. 2, No. 1, 2015

[11] M. Khalighi, N. Schwartz, N. Aitamer, and S. Bourennane, "Fading reduction by aperture averaging and spatial diversity in optical wireless systems,” J. Opt. Commun. Netw., vol. 1, no. 6, pp. 580-593, Nov. 2009.

[12] H. G. Sandalidis, T. A. Tsiftsis, G. K. Karagiannidis, and M. Uysal, "BER performance of FSO links over strong atmospheric turbulence channels with pointing errors," IEEE Commun. Lett., vol. 12, no. 1, pp. 44-46, Jan. 2008.

[13] A. A. Farid and S. Hranilovic, "Diversity gain and outage probability for MIMO free-space optical links with misalignment," IEEE Trans. Commun., vol. 60, no. 2, pp. 479-487, Feb. 2012.

[14] P. Kaur, V. K. Jain, and S. Kar,” Performance Analysis of FSO Array Receivers in Presence of Atmospheric Turbulence", IEEE Photonics Technology Letter, Vol. 26, No. 12, pp. 1165-1168, June, 2014

[15] A. Gupta , R S Kaler, H Singh, "Investigation of OBS assembly technique based on various scheduling techniques for maximizing throughput”, Optik-International Journal for Light and Electron Optics, 124(9), pp. 840-844, 2013

[16] A Gupta, RS Kaler, H Singh,” An inimitable scheduling technique for optical burst switched networks", Optik-International Journal for Light and Electron Optics, vol. 124, no. 8, pp.689-692, 2013

[17] A. K.Majumdar\& J. C. Ricklin, "Free space laser communications, principles and advantages”, Berlin: Springer, 2008

[18] S. Muhammad, B. Flecker, E. Leitgeb, \& M. Gebhart, "Characterization of fog attenuation in terrestrial free space optical links" Journal of Optical Engineering, vol. 46, no. 4, pp.1-9, 2007

[19] Akiba, M., Ogawa, K., Wakamori, K., Kodate, K., \& Ito, S, "Measurement and simulation of the effect of snowfall on free space optical propagation”, Journal of Applied Optics, Vol. 47, No. 31, pp. 5736- 5743, 2008

[20] Betti, S., Carrozzo, V., \& Duca, E. "Over stratospheric altitude optical free space links: System performance evaluation transparent optical networks". In ICTON, International Conference on Transparent Optical Networks, July 2007

[21] S. Bloom, E. Korevaar, J. Schuster and H. Willebrand, "Understanding the performance of free-space optics", Journal of Optical Networking, Vol. 2, No. 6, June 2003.

[22] M. Jeong, J. Lee, S. Kim, S. Namgung, J. Lee, M. Cho, S. Huh, Y. Ahn, J. Cho, and J. Lee, "Weather-Insensitive Optical Free-Space Communication Using Gain-Saturated Optical Fiber Amplifiers", IEEE Journal of Lightwave Technology, Vol. 23, No. 12, 2005.

[23] A. E. N. A Mohamed, H. A. Sharshar, A. N. Z. Rashed \& A. ElNabawy, " Integrated service quality enhancement of wireless optical communication systems for long haul transmission distances” Canadian Journal on Electrical and Electronics Engineering, vol. 2, no. 12, pp.557-570, 2011

[24] A Gupta, H Singh, J Kumar,” A novel approach to reduce packet loss in OBS networks” International Journal of Computer Applications, vol. 58, no. 3, 2012

[25] N. Vinayak, A gupta," Comparative analysis of WDM system using Cascaded amplifiers in Optical wireless channel over a distance of 10000 km”, SOP Transactions on Signal Processing, Vol. 1, No. 1, pp.25-32, 2014 